\title{
Nutritional Management of Multiple Pregnancies
}

\author{
Kerryn Roem \\ Department of Nutrition and Dietetics, Royal Women's Hospital, Melbourne
}

G ood nutrition is central to achieving optimal fetal growth and development, and to maintaining maternal health and wellbeing. For multiple pregnancies, there is a growing body of evidence linking good maternal nutrition and weight gain to positive perinatal outcomes including reduced incidence of low birthweight and very low birthweight infants. Nutrition intervention appears to have important clinical implications for infant morbidity and mortality. Nutritional counselling can help women improve and maximise their intake of "at risk nutrients" such as iron, folate, essential fatty acids, calcium and ensure adequate energy intake to meet weight gain targets. Recommended optimal weight gains range from $16-20 \mathrm{~kg}$ for twin pregnancies. Expert dietetic guidance is often warranted, especially for women expecting triplets or quadruplets.

During the past 20 years, the incidence of multiple births has risen dramatically as a result of the use of assisted reproductive technologies and a trend toward delaying childbirth. Multiple pregnancies represent one of the highest risk conditions faced in pregnancy (Newman, 1995). Intrauterine growth retardation and prematurity are major contributors to the increased perinatal morbidity and mortality seen in these pregnancies (Berry, 1995).

The importance of nutrition in pregnancy has been emphasised for many years. Good nutrition is central to achieving optimal fetal growth and development, and to maintaining maternal health and wellbeing (Position of the American Dietetic Association, 2002). In recent years, evidence is emerging that nutrition during fetal life and early infancy has an important impact on morbidity and mortality in adult life (Erikson et al., 2001). For multiple pregnancies, there is a growing body of research linking good maternal nutrition and weight gain to positive perinatal outcomes, including reduced incidence of low birthweight and very low birthweight infants, longer gestation, and greater birthweights (Dubois et al., 1991; Luke et al., 1992; Min et al., 2000). However, nutrition counselling and interventions are often overlooked in the prenatal care of multiples. This is unfortunate as nutrition intervention appears to have important clinical implications for infant morbidity, mortality and subsequent childhood growth and development (Luke et al., 1997).

While intakes of specific nutrients have been recommended for singleton pregnancies, there are no Australian or international recommended dietary intakes for women expecting twins, triplets, or higher order multiples. A review of the literature reveals a paucity of information on the changes in metabolism or the extent of nutrient requirements in multiple pregnancies. This paper summarises the current research available on nutrient requirements, weight gain and nutrition intervention studies. It also discusses some of the problems facing women with multiple pregnancies that can make meeting nutrient requirements and weight gain difficult.

\section{Nutrients}

Pregnancy increases the demand for many nutrients, particularly iron, folate, essential fatty acids, calcium, vitamin D and energy. Women with multiple pregnancies need to pay particular attention to these nutrients.

\section{Iron and Folate}

Demands for both iron and folate are significantly greater for multiple pregnancies in order to meet the needs of both the fetus and the mother. Maternal anaemias of both iron and folate deficiency are common. The incidence of megaloblastic anaemia in pregnancy secondary to folate deficiency has been reported to be eight times higher in multiple pregnancies (Berry, 1995). Mothers with twin pregnancies have iron deficiency anaemia 2.4 times more frequently than do women with singleton pregnancies (Spellacy et al., 1990).

The extent to which iron deficiency affects maternal and neonatal health is still uncertain. Existing data suggests that maternal iron deficiency anaemia may be associated with adverse outcomes such as preterm delivery, higher maternal mortality, poorer maternal immune status, lower birthweight and delayed psychomotor development in infants (Lindsay, 1997; Tsunenbu et al., 2002; Scholl et al., 1992; Kaltreider \& Johnson, 1976; Singla et al., 1978).

Because of the high incidence of iron deficiency anaemia in multiple pregnancies and the current evidence available regarding its detrimental effects, assessment of iron status and provision of appropriate therapy are important considerations for optimal prenatal care.

An early and thorough hematologic evaluation is important to establish the extent of iron stores at the onset of pregnancy. Haemoglobin, hematocrit and ferritin levels

Address for correspondence: Ms Kerryn Roem, Department of Nutrition and Dietetics, The Royal Women's Hospital, Melbourne, 132 Grattan Street, Carlton VIC 3053, Australia.

Email: roemk@ocean.com.au 
should be determined at the first prenatal visit. Haemoglobin concentrations alone are unreliable in pregnancy due to marked physiological changes in plasma volume and red cell mass (de Leeuw et al., 1974; Hall, 1974; Lind et al., 1975). Ferritin is the best indicator of storage iron in pregnancy (Van Den Broek et al., 1998).

Due to the high incidence of anaemia in multiple pregnancies, routine iron supplementation (30 to $60 \mathrm{mg} / \mathrm{d}$ ) is recommended (Hunter, 1989; Newman, 1995). Iron supplements are important to prevent development of anaemia even if iron stores are adequate in early pregnancy. Those women who are found to be anaemic in early pregnancy may need larger doses of supplemental iron.

It is advised to regularly check if women are taking these supplements as non-compliance with iron therapy is common (Galloway \& McGuire, 1994). Remeasuring haemoglobin and ferritin levels during the pregnancy is recommended to check for anaemia. From our experience low levels during pregnancy often reflect poor compliance.

Folate, required for deoxyribonucleic acid synthesis and cell division, plays a critical role in fetal development. Low folate status may increase the risk of preterm delivery, low birthweight and fetal growth restriction (Scholl \& Johnson, 2000). Supplementation with folate is also recommended in multiple pregnancies (American Institute of Medicine, 1990; Hunter, 1989; Smith-Levitin et al., 1999). The American Institute of Medicine (1990) recommends supplementation with 300 ug folate daily throughout pregnancy.

\section{Essential Fatty Acids}

Essential fatty acids (EFA) are important structural elements of cell membranes and therefore instrumental in the formation of new tissues. They are vital components of the brain and retina cells and play a potentially important role in the development of mental and visual function. Certain long chain polyunsaturates are also required for the synthesis of prostaglandins.

The developing fetus depends on the mother for an adequate supply of EFA (Hornstra, 2000). Studies have found lower levels of essential fatty acids in women with multiple pregnancies and lower EFA status in their infants, and note the potential for impaired growth and neurological development in these offspring (Froemn-v. Drongelen et al., 1996; Zeijdner et al., 1997). Of particular relevance to multiple pregnancies is the effect EFA may have on the duration of pregnancy. A recent trial by Olsen et al. (1992) looked at the effect of fish oil supplementation on pregnancy duration in singleton pregnancies. This study showed promising effects on pregnancy duration (on average 4 days longer with fish oil); the difference in birthweight was $107(1-214) \mathrm{g}$. While more randomised controlled trials are needed before supplementation can be recommended, it seems prudent at this stage to advise women to increase their consumption of EFA from food during pregnancy. The best sources of essential fatty acids are fresh or canned oil-rich fish such as salmon, tuna, sardines, mackerel and herrings. Women are advised to eat these fish two to three times a week (Rice, 1996). Other sources for women who do not eat fish include walnuts, spinach and canola oil or canola margarine.

\section{Calcium}

Calcium accretion during pregnancy totals approximately $30 \mathrm{~g}$ in singletons, mostly in the fetal skeleton, and is deposited during the last trimester. It has been found that the concentration of 1,25-dihdroxyvitamin D3 is raised during pregnancy, increasing net calcium absorption (Misra \& Anderson, 1990). Calcium excretion during pregnancy decreases. The requirement for calcium during pregnancy may be met either partly or entirely by these mechanisms. However the extent to which calcium absorption increases and excretion decreases to support the developing skeletons of more than one fetus is not known. Additional calcium may be required in order to meet requirements. As well as consuming the 2 to 3 serves of dairy foods a day suggested for singleton pregnancies, it is recommended women with multiples take a calcium supplement (Smith-Levitin, 1999).

\section{Vitamin D}

Vitamin D is important in order to sustain the heightened calcium absorption and utilisation during pregnancy. Normally, the body's requirements for vitamin D are supplied through exposure to sunlight, but whether the increased needs during multiple pregnancies can be met via this route remains unclear.

A risk factor for poor vitamin D status in early infancy is maternal vitamin D deficiency during pregnancy, resulting in an inadequate transfer of vitamin $D$ to the fetus and low infant stores (Specker, 1994; Zeghoud, 1997). Babies born to women with low vitamin D levels are at a high risk of developing rickets (Zozza \& Rodda, 2001). Women at particular risk of vitamin D deficiency include dark skinned and/or women with limited sun exposure because of veiling (Nesby et al., 2002; Grover \& Morley, 2001). In a recent study conducted in Australia, vitamin D deficiency was detected in up to $80 \%$ of dark-skinned and /or veiled women during singleton pregnancies (Grover \& Morley, 2001). Therefore it is strongly recommended that all dark skinned and/or veiled women with multiple pregnancies be screened for vitamin D deficiency and supplemented as necessary (Nozza \& Rodda, 2001).

Little data exists for recommendations of levels of other vitamins and minerals. Careful attention to diet is important. Women need to consume a variety of nutrient dense foods to maximise their intake of nutrients. In addition to the supplements recommended above, the American Dietetic Association recommends that all women with multiple pregnancies take a daily multivitamin and mineral supplement (Position of the American Dietetic Association, 2002). Supplements should be those without Vitamin A in the retinol form, because of its potential teratogenicity.

\section{Energy and Macronutrients}

Additional energy is required during pregnancy because of increases in maternal tissues (especially the uterus and breasts) and the growth and development of the fetus and placenta. The extent of additional requirements in multiple pregnancies is unknown. Brown and Carlson (2000) have estimated energy requirements from data on weight gain in 
twin pregnancies and suggest a level of 630 kilojoules per day above the level of singleton pregnancies. Because it is difficult to accurately assess energy requirements, they recommend that energy adequacy could be assessed, in general, by monitoring weight gain progress.

The requirements for protein, fat and carbohydrate in multiple pregnancies are not known. No studies exist to support recommended levels of these nutrients (Brown \& Carlson, 2000).

\section{Weight Gain}

The issue of optimal weight gain has been controversial for many years and remains so. There is a growing body of evidence that indicates weight gain is an important factor in perinatal outcome in multiple pregnancies. Currently there have been few controlled studies conducted; most of the data available comes from historical or retrospective studies.

From the evidence available, infants show a marked advantage when total weight gain, and specifically early weight gain is higher than the mean values associated with singleton pregnancies. Total weight gains of at least 16-20 $\mathrm{kg}$ are recommended (Brown \& Schloesser, 1990; Luke et al., 1992; Luke \& Leurgans, 1996; Pederson et al., 1989). These higher weight gains have been associated with birthweights of $>2500 \mathrm{~g}$ at 36-38 weeks (Brown \& Schloesser, 1990; Luke et al., 1992; Luke \& Lergans, 1996). The effect of weight gain on infant birthweight is more pronounced in underweight and normal weight women than in overweight women (Brown \& Schloesser, 1990; Fenton \& Thirsk, 1994; Luke et al., 1997; Lantz et al., 1996). It has been suggested that this may be due in part to the fact that overweight and obese women already have the additional fat stores that are part of the physiologic weight gain during pregnancy for underweight and normal weight women, diminishing the effect of their gains on birthweights (Luke et al., 1997). Although the effect of weight gain on birthweight is diminished in overweight women, there still appears to be a need for some weight gain (Luke et al., 1992). Underweight women are advised to gain at the higher end of the recommended weight gain range and obese or overweight women at the lower end.

While there have been limited studies conducted in triplet pregnancies, a gain of $-22 \mathrm{~kg}$ by 33 weeks has been recommended (Luke et al., 1995).

The pattern and rate of weight gain also appear to be important. Several studies have clearly established the importance of maternal weight gain before 20 weeks on twin birthweight (Luke et al., 1992; Luke et al., 1993; Luke et al., 1997; Luke et al., 1998). A low rate of gain $(<6 \mathrm{~kg})$ before 24 weeks is significantly associated with poor fetal growth and higher morbidity (Luke et al., 1992; Luke et al., 1993; Luke et al., 1997; Luke et al., 1998). It has been suggested that higher weight gains during early gestation may influence the structural and functional development of the placenta (Newman \& Luke, 2000). In multiple pregnancies where the placenta ages more quickly, this initial benefit to the placenta may augment fetal growth through more effective placental function and transfer of a higher level of nutrients later in pregnancy (Newman \& Luke, 2000).
Other studies have shown that mid-gestational weight gain, between 20 and 28 weeks, is also important, significantly affecting the rate of fetal growth between 20 weeks and delivery (Lantz et al., 1996, Luke et al., 1992; Luke et al., 1993). It appears a consistent gain in weight throughout pregnancy is advisable (Brown \& Carlson, 2000).

Underweight women are at high risk of delivering preterm and require special attention (Eller et al., 1993; Position of the American Dietetic Association, 2002). There is evidence from Singleton pregnancies that underweight women have an increased risk of preterm birth, small for gestational age and/or low birthweight babies (Hickey et al., 1997; Kramer et al., 1995; Kirchengast \& Hartmann, 1998; Meis et al., 1995). This has also been our experience with underweight women carrying multiples. These women need to be monitored closely to ensure they are obtaining adequate energy and meeting weight gain targets.

Weight loss needs to be avoided in multiple pregnancies. Konwinski et al. (1973) reported that twins were three times more likely to be born prematurely to women of any weight who lost weight after 28 weeks gestation.

\section{Factors Affecting Food Intake}

While both the need for nutrients and weight gain appear to be higher in multiple pregnancies, meeting these requirements can be a challenge. Factors such as nausea, vomiting, heartburn and constipation can make meeting requirements difficult. While these factors are not unique to multiple pregnancies, they tend to be more common and more severe than in singleton pregnancies (Mariano \& Hickey, 1998). It is therefore vital that these symptoms be treated and not ignored.

Two factors however that are not often experienced in singleton pregnancies but have a big impact on nutrition in multiple pregnancies are poor appetite and early satiety. These are common in the third trimester as an expanding uterus reduces stomach capacity. While small frequent meals or "grazing" all day can help increase intake, they may still not provide the required energy. As a result many women with twins will require some type of high energy, high protein nutritional supplement drink, usually from around 28-30 weeks gestation. From our experience, all women with triplets will require supplements at -24-25 weeks gestation.

A very small percentage of women will experience vomiting after eating. This occurs mainly in the third trimester due to a reduced stomach capacity. Changing the consistency of meals can help reduce the frequency and severity of vomiting. Supplementing meals with high energy, high protein drinks allows a continual intake of nutrients and energy as drinks are less likely to be vomited.

For all these reasons, many women expecting multiples will benefit from a consultation with a dietitian. A referral is especially important for women expecting higher order multiples as these factors present even more of a problem in these pregnancies.

\section{High Risk Groups}

Some women will require more targeted advice in order to counter individual nutritional problems or inadequacies, 
ideally at the onset as well as during the pregnancy. Women who are particularly at higher nutritional risk are those who:

- suffer from hyperemesis and in whom nutrient stores may be quickly depleted

- are adolescents and may still be growing and therefore need to meet requirements for both growth and the pregnancy

- are from ethnic minority groups, especially recent immigrants or those with English language difficulties

- are vegans or vegetarians who follow an inadequate diet. The main nutritional concerns for pregnant vegetarians are iron and vitamin B12. Because of the serious consequences of vitamin B12 deficiency for the newborn (English, 1990), it is recommended that all pregnant vegetarians/vegans have B12 levels monitored regularly throughout pregnancy and if levels are falling take additional supplements of this nutrient

- have closely spaced pregnancies

- have, or have a recent history of, an eating disorder such as anorexia nervosa or bulimia nervosa or have extreme body image concerns

- are restricting their food intake for reasons such as slimming or self-diagnosed "food allergies"

- are underweight.

\section{Nutrition Intervention Studies}

A body of research is beginning to emerge that indicates the value of nutrition intervention in the management of multiple pregnancies (Dubois et al., 1991; Min et al., 2000; Newman \& Luke, 2000). The Higgins Nutrition Intervention program (Dubois et al., 1991) recommends an additional 4200 kilojoules and $50 \mathrm{gms}$ protein in addition to baseline singleton dietary recommendations. This program has demonstrated improvements in birthweights, reductions in low birthweights and reductions in preterm ( $<37$ weeks) births in mothers of twins who were in the intervention program compared to women who were not in the program. Min et al. (2000) found that participation in a prenatal nutrition education program was associated with dramatic reductions in neonatal morbidity as evidenced by shorter newborn length of stay. Luke et al. (1997) demonstrated that mothers who received their nutrition advice from a registered dietitian had the highest maternal weight gains and lowest proportion of infant birthweights $<1500 \mathrm{~g}$.

\section{Other Considerations \\ Listeriosis}

Listeriosis infection of the fetus can lead to abortion, stillbirth or delivery of an acutely ill infant (Miriam et al., 1994). A study by Mascol et al (1994) found that pregnant women with multiples had a nearly fourfold greater risk of listeriosis than singletons. It has been proposed that this higher incidence may be due to a relatively greater immunosuppression in women with multiple pregnancies (Craig et al., 1996). All pregnant women, especially those with multiple pregnancies, need to be advised to avoid foods which could contain significant amounts of the organism.

\section{Mercury in Fish}

There is some research that indicates fetuses may be more sensitive than adults to the effects of mercury from food consumption (Castoldi et al., 2001; Shipp et al., 2000). These effects are generally not apparent until after the baby is born and typically manifest as subtle delays in the achievement of developmental milestones. The Australian New Zealand Food Authority (2001) recommends that pregnant women should limit their consumption of some types of fish. Fish with higher levels of mercury are those at the top of the food chain, or living in geothermal waters. In Australia these are: shark/flake, ray, swordfish, barramundi, gemfish, orange roughy, ling, and southern bluefin tuna. Women are advised to limit their intake to four portions per week (an average portion would contain about $150 \mathrm{~g}$ of fish). Other fish, including canned tuna, can be consumed as often as desired.

\section{Conclusion}

Nutrition assessment and education are important components of the prenatal care of multiple pregnancies. Nutrition may provide a simple but powerful mechanism to improve intrauterine growth and length of gestation in these high-risk pregnancies. From the evidence available there is a need for increased nutrients particularly iron, folate, essential fatty acids, calcium, vitamin D and energy. Both total weight gain and rate of weight gain are important elements to be managed. Nutritional counselling helps women maximise their energy and nutritional intake and meet weight gain targets. Expert dietetic guidance is warranted for women suffering from poor appetite or early satiety. For women carrying triplets and higher order multiples dietetic intervention is vital.

\section{$\overline{\text { Acknowledgments }}$}

Thanks are due to Mary Anne Silvers, Elisabeth Gasparini and Jenny Taylor for their review of this manuscript and valuable suggestions.

\section{References}

American Institute of Medicine (1990). Nutrition during pregnancy. Washington, DC: National Academy Press.

Australian New Zealand Food Authority. (2001). Mercury in fish - Advisory statement for pregnant women. Canberra: Author.

Berry, C. (1995). Megaloblastic anaemia in pregnancy. Clinical Obstetrics and Gynecology, 38(3), 455-462.

Brown, J., \& Carlson, M. (2000). Nutrition and multifetal pregnancy. Journal of the American Dietetic Association, 100(3), 343-348.

Brown, J., \& Schloesser, P. (1990). Prepregnancy weight status, prenatal weight gain, and the outcome of term twin gestations. American Journal of Obstetrics and Gynecology, 162, 182-186.

Castoldi, A., Coccini, T., Ceccatelli, S., \& Manzo, L. (2001). Nuerotoxicity and molecular effects of methymercury. Brain Research Bulletin, 55(2), 197-203. 
Craig, S., Permezel, M., Doyle L., Mildenhall L., \& Garland S. (1996). Perinatal infection with listeria monocytogenes. Australian and New Zealand Journal of Obstetrics and Gynaecology, 36(3), 286-290.

deLeeuw, N. K. , Lowenstein, L. \& Hseih, Y. S. (1974). Iron deficiency anemia and hydremia in normal pregnancy. Medicine (Baltimore), 45, 291-315.

Dubois, S., Dougherty, C., Duquette, M., Hanley, J., \& Moutquin, J. (1991). Twin pregnancy: The impact of the Higgins Nutrition Intervention Program on maternal and neonatal outcomes. American Society for Clinical Nutrition, 53, 1397-1403.

Eller, D., Newman, R., Ellings, J., Campbell, B., \& Clinton Miller, M. (1993). Modifiable determinants of birthweight variability in twins. Journal of Maternal-Fetal Medicine, 2, 254-259.

English, R. (1990). Vitamin B12. In Committee on Dietary Allowances (Eds.), Recommended nutrient intakes (pp. 110-119). Washington, DC: National Academy of Sciences.

Erikson J., Forsen T., Tuomilehto J., Osmond C., \& Barker D. (2001). Early growth and coronary heart disease in later life: Longitudinal study. British Medical Journal, 322, 949-953.

Fenton, T., \& Thirsk, J. (1994). Twin pregnancy: The distribution of maternal weight gain of non-smoking normal weight women. Canadian Journal of Public Health, 85(1), 37-40.

Foreman-v. Drongelen, M., Zeijdner, E., Houwelingen, A., Kester, A., Al, M., Hasaart, T., \& Hornstra, G. (1996). Essential fatty acids status measured in umbilical vessel wall of infants born after a multiple pregnancy. Early Human Development, 46, 205-215.

Galloway R., \& McGuire, J. (1994). Determinants of compliance with iron supplementaion: Supplies, side effects, or psychology? Social Science and Medicine, 3(3), 381-390.

Grover, S., \& Morley, R. (2001). Vitamin D deficiency in veiled or dark-skinned pregnant women. Medical Journal of Australia, 175, 251-252.

Hall, H. (1974). Pregnancy anaemia. British Medical Journal, ii, 661-663.

Harrison, K., \& Ibeziako, P. (1973). Maternal anemia and fetal birthweight. Journal Obstetrics and Gynaecology of the British Commonwealth, 80, 798-804.

Hickey, C., Cliver, S., McNeal, S., \& Goldenberg, R. (1997). Low pregravid body mass index as a risk factor for preterm birth: Variation by ethnic group. Obstetrics and Gynecology, 89(2), 206-212

Hornstra, G. (2000). Essential fatty acids in mothers and their neonates. American Journal of Clinical Nutrition, 71(suppl), $1262 \mathrm{~s}-1269 \mathrm{~s}$

Newman, R. (1995). Antepartum management of the multiple gestation. The case for specialised care. Seminars in Perinatology, 19(5), 387-403.

Hunter, L. (1989). Twin gestation: Antepartum management. Perinatal Neonatal Nursing, 3(1), 1-13.

Kaltrieder, D., \& Johnson, J. (1976). Patients at high risk for low birthweight delivery. American Journal of Obstetrics and Gynecology, 124, 251-256.

Kirchengast, S., \& Hartmann, B. (1998). Maternal prepregnancy weight status and pregnancy weight gain as major determi- nants for newborn weight and size. Annals of Human Biology, 25(1), 17-28.

Konwinski, T., Gerard, C., Hult, A., \& Papiernik-Berkhauer, E. (1973). Maternal pregestational weight and multiple pregnancy duration. Acta Geneticae Medicae et Gemellologiae, 22(Suppl.), 44-47.

Kramer, M., Coates, A., Michoud, M., Dagenais, S., Hamilton, E., \& Papageorgiou, A. (1995). Maternal anthropometry and idiopathic preterm labor. Obstetrics and Gynecology, 86(5), 744-748.

Lantz, M., Chez, R., Rodriguez, A., \& Porter, K. (1996). Maternal weight gain patterns and birthweight outcome in twin gestation. Obstetrics and Gynecology, 87(4), 551-556.

Lind, J., Hytten, F. E., \& Thomson, A. M. (1975). Anaemia in pregnancy. British Medical Journal, ii, 627.

Lindsay, A. (1997). Pregnancy and iron deficiency: Unresolved issues. Nutrition reviews; 55(4), 91-101.

Luke, B., Bryan, E., Sweetland, S., Leurgans, S., \& Keith, L. (1995). Prenatal weight gain and the birthweight of triplets. Acta Geneticae Medicae et Gemellologiae, 44(2), 93-101.

Luke, B., Gillespie, B., Min, S. J., Avni, M., Witter, F., \& O'Sullivan, J. (1997). Critical periods of maternal weight gain: Effect on twin birthweight. American Journal of Obstetrics and Gynecology, 177(5), 1055-1062.

Luke, B., Keith, L., \& Keith, D. (1997). Maternal nutrition in twin gestations: Weight gain, cravings and aversions, and sources of nutrition advice. Acta Geneticae Medicae et Gemellologiae, 46, 157-166.

Luke, B., \& Leurgans, S. (1996). Maternal weight gains in ideal twin outcomes. Journal of the American Dietetic Association, 96(2), 178-181.

Luke, B., Min, S.J., Gillespie, B., Avni, B., Witter, F., Newman, R., et al. (1998). The importance of early weight gain in the intrauterine growth and birthweight of twins. American Journal of Obstetrics and Gynecology, 179, 1155-1161.

Luke, B., Minogue, J., Abbey, H., Keith, L., Witter, F., Fing, T., \& Johnson, T. (1992). The association between weight gain and the birthweight of twins. Journal of Maternal-Fetal Medicine, 1, 267-276.

Luke, B., Minogue, J., Witter, F., Keith, L., \& Johnson, T. (1993). The ideal twin pregnancy: Patterns of weight gain, discordancy and length of gestation. American Journal of Obstetrics and Gynecology, 169(3), 588-597.

Mariano, C., \& Hickey, R. (1998). Multiple pregnancy, multiple needs. The Canadian Nurse, 94(9), 26-30.

Mascola, L., Ewert, P., \& Eller, A. (1994). Listeriosis: A previously unreported medical complication in women with multiple gestations. American Journal of Obstetrics and Gynaecology, 170(5), 1328-1332.

Meis, P., Michielutte, R., Peters, T., Wells, B., Sands, E., Coles, E., et al. (1995). Obstetrics. Factors associated with preterm birth in Cardiff, Wales. II. Indicated and spontaneous preterm birth. American Journal of Obstetrics and Gyneocology, 173(2), 597-602.

Min, L., Misiunas, R., Luke, B., \& Hillemeier, M. (2000). Improving outcomes in twin pregnancies: Maternal and neonatal hospital charges and length of stay. American Journal of Obstetrics and Gynecology, 182(2), S141. 
Miriam, P., Dwyer, D., Chow, C., Robson, J., Chambers, I., Eagles, G., et al. (1994). Listeriosis - A review of eighty-four cases. The Medical Journal of Australia, 160, 489-493.

Misra, R., \& Anderson, D. C. (1990). Providing the fetus with calcium. British Medical Journal, 30, 1220-1221.

Nesby, S. S., Scanlon, K., Cogswell, M., Gillespie, C., Hollis, B., Looker, A., et al. (2002). Hypovitaminosis D prevalence and determinants among African American and white women of reproductive age: Third National Health and Nutrition Examination Survey, 1988-19945. American Journal of Clinical Nutrition, 76, 187-192.

Newman, R., \& Luke, B. (2000). Multifetal pregnancy: A handbook for care of the pregnant patient (pp. 95-123). Philadelphia: Lippincott Williams and Wilkins.

Nozza, M., \& Rodda, C. (2001). Vitamin D deficiency in mothers of infants with rickets. Medical Journal of Australia, $175,253-255$.

Olsen, S., Sorensen, J., Secher, N., Hedegaard, M., Henriksen, T., Hansen, H., \& Grant, A. (1992). Randomised controlled trial of effect of fish-oil supplementation on pregnancy duration. The Lancet, 339, 1003-1007.

Pederson, A., Worthington-Roberts, B., \& Hickok, D. (1989). Weight gain patterns during twin gestations. Journal of the American Dietetic Association, 89(5), 642-646.

Position of the American Dietetic Association (2002). Nutrition and lifestyle for a healthy pregnancy outcome. Journal of the American Dietetic Association, 102(10), 1479-1490.

Rice, R. (1996). Fish and healthy pregnancy: More than just a red herring! Professional Care of Mother and Child, 6(6), 171-173.

Scholl, T., Hediger, M., Fischer, R., \& Shearer, J. (2002). Anemia versus iron deficiency: Increased risk of preterm delivery in a prospective study. American Journal of Clinical Nutrition, 55, 985-988.

Scholl, T., \& Johnson, W. (2000). Folic acid: Influence on the outcome of pregnancy. American Journal of Clinical Nutrition, $71,1304 s-1307 s$.
Shipp, A., Gentry, P., Lawrence, G., Van Landingham, C., Covington, T., Clewell, H., et al. (2000). Determination of a site-specific reference dose for methylmercury for fish-eating populations. Toxicology and Industrial Health, 16, 335-438.

Singla, P., Chand, S., Khanna, S., \& Agarwal, K. (1978). Effect of maternal anemia on the placenta and the newborn infant. Acta Paediatrica Scandinavica, 67, 645-648.

Smith-Levitin, M., Skupski, D., \& Chervenak, F. (1999). Multifetal Pregnancies: Epidemiology, clinical characteristics and management. In E. A. Reece, \& J. Hobbins (Eds.), Medicine of the mother and fetus (2nd ed.; pp. 243-265). Philadelphia: Lippincott-Raven Publishers.

Specker, B. L. (1994). Do North American women need supplemental vitamin D during pregnancy or lactation? American Journal of Clinical Nutrition, 59(suppl), 484s-491s.

Spellacy, W., Handler, A., \& Ferre, C. (1990). A case controlled study of 1253 twin pregnancies from 1982-1987. Perinatal database. Obstetrics and Gynecology, 75(2), 168-171.

Tsunenobu, T., Goldenberg, R., Hou, J., Johnston, K., Cliver, S., Ramey, S., et al. (2002). Cord serum ferritin concentrations and mental and psychomotor development of children at five years of age. Journal of Pediatrics, 140, 165-170.

Van Den Broek, N., Letsky, E., White, S., \& Shenkin, A. (1998). Iron status in pregnant women: Which measurements are valid? British Journal of Haematology, 103, 817-824.

Zeghoud, F., Vervel, C., Guillozo, H., Walrant-Debray, O., Boutignon, H., \& Garabedian, M. (1997). Subclinical vitamin $\mathrm{D}$ deficiency in neonates: Definition and response to vitamin D supplements. American Journal of Clinical Nutrition, 65, 771-778.

Zeijdner, E., Houwelingen, A., Kester, A., \& Hornstra, G. (1997). Essential fatty acid status in plasma phospholipids of mother and neonate after multiple pregnancy. Prostaglandins, Leukotrienes and Essential Fatty Acids, 56(5), 395-401. 